\title{
New techniques for wound management: A systematic review of their role in the management of chronic wounds
}

\author{
Farid Bekara ${ }^{1,2}$, Julian Vitse ${ }^{1}$, Sergiu Fluieraru ${ }^{1}$, Raphael Masson ${ }^{1,3}$, Antoine De Runz ${ }^{4}$, \\ Vera Georgescu ${ }^{5}$, Guillaume Bressy, ${ }^{2,6}$, Jean Louis Labbé ${ }^{2}$, Benoit Chaput ${ }^{7}$, Christian Herlin ${ }^{1}$ \\ ${ }^{1}$ Department of Plastic and Reconstructive Surgery, Wound Healing and Burns Units, Lapeyronie University Hospital, Montpellier, France; \\ ${ }^{2}$ Department of Orthopedics and Traumatology, Gaston Bourret Territorial Hospital, Nouméa, New Caledonia; ${ }^{3}$ Department of Infectious \\ Disease, Gui de Chauliac University Hospital, Montpellier; ${ }^{4}$ Department of Maxillofacial, Plastic, Reconstructive and Cosmetic Surgery, \\ Nancy University Hospital, Nancy; ${ }^{5}$ Department of Biostatistics and Medical Information, Lapeyronie University Hospital, Montpellier; \\ ${ }^{6}$ Department of Orthopedics and Traumatology, Reims University Hospital, Reims; ${ }^{7}$ Department of Plastic and Reconstructive Surgery, \\ Rangueil University Hospital, Toulouse, France
}

Debridement is a crucial component of wound management. Recent technologies such as hydrosurgery (Versajet), ultrasound therapy (the MIST therapy device), or plasma-mediated bipolar radio-frequency ablation therapy (Coblation) seem to represent interesting alternatives for wound debridement. The purpose of this systematic review was to describe, evaluate, and compare these three recently developed methods for the management of chronic wounds. In January 2016, an electronic database search was conducted of MEDLINE, PubMed Central, and Embase for articles concerning these three innovative methods for the management of chronic wounds. A total of 389 references were identified by our search strategy, and 15 articles were included. We extracted data regarding the number and age of patients, indications, operating time, number of procedures, costs, wound healing time, decrease in exudation, perioperative blood loss, bacterial load, and the occurrence of complications. The 15 articles included studies that involved 563 patients who underwent hydrosurgery (7 studies), ultrasound therapy (6 studies), or Coblation (2 studies). Six randomized controlled trials were included that compared the use of a scalpel or curette to hydrosurgery (2 studies) or ultrasound therapy ( 6 studies). Hydrosurgery, in addition to being a very precise and selective tool, allows significantly faster debridement. Ultrasound therapy provides a significant reduction of exudation, and improves the wound healing time. No comparative study dedicated to Coblation was identified. Despite the obvious clinical interest of the topic, our review of the current literature revealed a lack of prospective randomized studies comparing these devices with each other or with standard techniques, particularly for Coblation and hydrosurgery.

Keywords Review / Debridement / Wound healing / Bacterial load / Hemorrhage
Correspondence: Farid Bekara Department of Plastic and Reconstructive Surgery, Wound Healing and Burns Units, Lapeyronie University Hospital, Avenue du doyen Gaston GIRAUD, Montpellier 34295, France

Tel: +33-4-6733-0589

Fax: +33-4-6733-0590

E-mail: farid.bekara@live.fr

This article contains Supplemental Videos S1-S3. 


\section{INTRODUCTION}

Wound debridement consists of removing necrotic or devitalized tissue and reducing the bacterial load. It is an essential step to bring about wound healing. Numerous debridement methods exist, such as autolytic [1], enzymatic [2], biodebridement [3], and surgical/sharp [4] and mechanical methods. Although sharp debridement using a scalpel or curette remains the gold standard [4], these techniques have several disadvantages. They are not appropriate for large surfaces, are not optimal for saving tissue, and they often lead to an uneven wound bed.

Recent innovations, such as hydrosurgery (Versajet) [5], ultrasound therapy (the MIST therapy device), [6] and plasma-mediated bipolar radio-frequency ablation therapy (Coblation) [7] could represent an alternative to conventional debridement in many cases, especially for chronic non-healing wounds. Those methods remain more expensive, but could be seen as more efficient than conventional techniques. The purpose of this systematic review was to describe and compare these three recently developed methods and to identify the particular benefits of each device.

\section{MATERIALS}

We compared three recently developed methods for wound management: hydrosurgery (Versajet hydrosurgery system), ultrasound (the MIST therapy device), and plasma-mediated bipolar radio-frequency ablation (Coblation).

\section{Hydrosurgery}

The Versajet hydrosurgery system (Smith \& Nephew, London, $\mathrm{UK}$ ) is a hydrosurgical device based on the principle of the Venturi effect. Saline solution is forced through a narrow window at high velocity, creating a localized vacuum. The suction permits targeted tissue to be cut while aspirating debris from the site (Supplemental Video S1).

\section{Ultrasound}

The MIST therapy device (Celleration, Eden Prairie, MN, USA) is intended to promote healing in chronic wounds. The manufacturer claims that the atomized saline acts as a conduit for ultrasound waves to reach the treatment site and that wound healing is promoted through debridement (i.e., the removal of fibrin, tissue exudates, and bacteria) (Supplemental Video S2).

\section{Plasma-mediated bipolar radio-frequency ablation} Coblation (Arthrocare ENT, Austin, TX, USA) uses bipolar radio-frequency to energize molecules via a conductive solution surrounding an active electrode, which creates a precisely focused plasma field. The glow discharge plasma produces chemically active radical species from the dissociation of water, breaking molecular bonds and causing tissue dissolution (Supplemental Video S3).

\section{METHODS}

\section{Study design}

A systematic review of the literature was conducted using the MEDLINE, PubMed Central, and Embase databases. The research period was not limited. This review was conducted in line with the recommendations specified in the Cochrane Handbook for Systematic Reviews of Interventions version 5.1.0, was AMSTAR-compliant, and was reported in accordance with the Preferred Reporting Items for Systematic Reviews and Meta-Analysis (PRISMA) statement. Informed consent was obtained from the patient or informed consent have been waived.

\section{Inclusion criteria}

All original studies describing hydrosurgery, ultrasound therapy, or plasma-mediated bipolar radio-frequency ablation were included. Duplicate studies, review articles, editorial/discussions/ commentaries, letters, purely technical descriptions, and animal studies were excluded.

\section{Search strategy}

In January 2016, an electronic database search was conducted of MEDLINE, PubMed Central, and Embase. This search was conducted using appropriate keywords in the English language with Boolean logical operators as follows: "Versajet" OR "Hydrosurgery" [Title/Abstract/MeSH Terms], "Arthrocare" OR "Plasma-mediated bipolar radio-frequency ablation" OR "Coblation technology" OR "Bipolar radio-frequency plasma” OR "Electrochemical debridement" [Title/Abstract/MeSH Terms], "Ultrasonic" OR "Ultrasonic MIST therapy" OR "Noncontact low frequency" [Title/Abstract/MeSH Terms]. There were no limits on research; non-English articles were translated, including Chinese articles. Data concerning only burns were excluded.

\section{Data extraction}

Data extraction was performed independently by two researchers (FB and JV) and discrepancies were resolved by consensus. If this was not possible, one of the senior authors $(\mathrm{CH})$ was asked to make the final decision. The extracted data were the number and age of patients, indications, operating time, number of procedures, and complications. The methodological quality 
of studies was assessed using the levels of evidence defined by the Oxford Centre for Evidence-Based Medicine [8].

\section{Practical approach}

The analysis of this review and the extrapolation of our experience with these three procedures have allowed us to identify a practical approach.

\section{RESULTS}

A total of 389 references were identified by our search strategy, including seven studies of hydrosurgery, six of ultrasound, and two of plasma-mediated bipolar radio-frequency ablation that met our criteria for inclusion. Fig. 1 shows how studies were selected through the processes of identification, screening, and eligibility, with 15 studies [9-23] finally included in this review.

\section{Population}

The 15 articles included studies that involved 563 patients (Table 1). We analyzed seven articles [9-15] investigating hydrosurgery, including 255 patients with an average age of 56.1 years (range, 1-79 years). The level of evidence was low to moderate. For ultrasound therapy, six articles [16-21] were screened. A total of 296 patients with an average age of 68.1 years (range, 4078 years) were treated. One study [16] had a high level of evidence (Table 2). Concerning Coblation therapy, only two arti- cles $[22,23]$ were selected, including 31 patients. The level of evidence was low.

\section{Procedures}

For hydrosurgery, one procedure was performed for $86.3 \%$ of patients (220/255) and several procedures were necessary for $13.7 \%$ (35/255). For ultrasound therapy, the number of required procedures was highly variable across studies, ranging from 1 to 10. Finally, for Coblation therapy, in most of the cases, one procedure was necessary (Table 1 ).

\section{Operating time}

Caputo et al. [10] found that on an average, hydrosurgery debridement was significantly faster than classic sharp debridement (10.8 minutes vs. 17.7 minutes). Gurunluoglu [9] gave a mean time to debride the wound of 15.5 minutes, but these results were not accompanied by data regarding the surface area of the wounds. For ultrasound therapy, the operating time varied depending on the team [16-20], ranging from 3 to 20 minutes. No data were found for Coblation therapy (Tables 2 and 3 ).

\section{Cost efficiency}

Concerning hydrosurgery, the authors $[10,14]$ emphasized the indirect financial gains of saving operating time, which allowed the treatment of more patients in the same operating schedule. The financial analysis of ultrasound therapy by Honaker et al.

\section{Fig. 1. Flow chart of article research and inclusion}

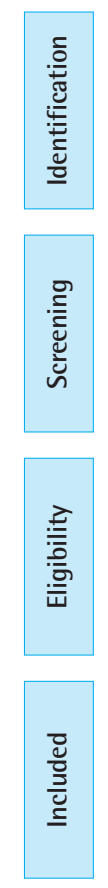

387 Records identified through PubMed database searching

2 Additional records identified through other sources

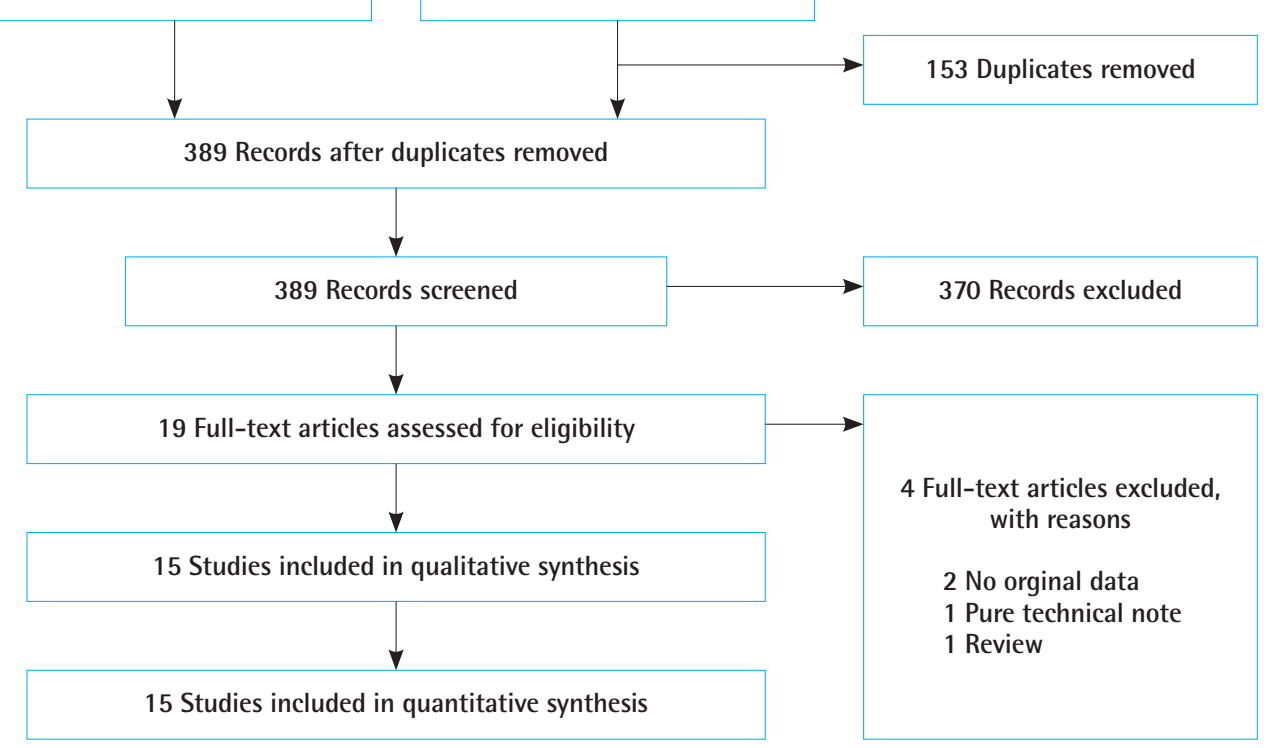


Table 1. Characteristics of included studies

\begin{tabular}{|c|c|c|c|c|c|c|c|c|}
\hline Technique & Study (year) & Grade & $\begin{array}{c}\text { No. of } \\
\text { patients }\end{array}$ & Age $(y r)^{a)}$ & Indication & Procedure & $\begin{array}{l}\text { Operative } \\
\text { time }(\min )^{\text {b) }}\end{array}$ & Complications \\
\hline \multirow[t]{19}{*}{ Hydrosurgery } & Gurunluoglu, 2007 [9] & C & 15 & 39.1 & Traumatic $(n=10)$ & & 15.5 & Incomplete graft take $(n=3)$ \\
\hline & & & & & Ulcer $(n=2)$ & $1(n=10)$ & & \\
\hline & & & & & Pressure sore $(n=1)$ & $2(n=4)$ & & \\
\hline & & & & & Burn $(n=1)$ & $3(n=1)$ & & \\
\hline & & & & & Infectious $(n=1)$ & & & \\
\hline & Caputo et al., 2008 [10] & $\mathrm{B}$ & 19 & 68 & Ulcer & $1(n=21)$ & 10.8 & No \\
\hline & & & & & & $2(n=1)$ & & \\
\hline & Dillon et al., 2010 [11] & C & 6 & 26.3 & Infectious & 1 & ND & No \\
\hline & Vanwijck et al., 2010 [12] & C & 167 & 56 & Ulcer $(n=122)$ & 1 & ND & Incomplete graft take $(n=8)$ \\
\hline & & & & & Pressure sore $(n=28)$ & & & \\
\hline & & & & & Traumatic $(n=13)$ & & & \\
\hline & & & & & Infectious $(n=4)$ & & & \\
\hline & Fraccalvieri et al., 2011 [13] & B & 27 & 69.4 & Ulcer $(n=16)$ & 1 & ND & No \\
\hline & & & & & Infectious $(n=6)$ & & & \\
\hline & & & & & Pressure sore $(n=5)$ & & & \\
\hline & Liu et al., 2015 [14] & B & 21 & 52.2 & Ulcer $(n=17)$ & 1 & 14.2 & No \\
\hline & & & & & Dehiscence $(n=3)$ & & & \\
\hline & & & & & Traumatic $(n=1)$ & & & \\
\hline & Sivrioglu et al., 2014 [15] & C & 9 & 2.5 & Extravasation injury & 1 & ND & No \\
\hline \multirow[t]{6}{*}{ Ultrasound } & Ennis et al., 2005 [16] & A & 55 & ND & Ulcer & $3 / w k$ & 4 & No \\
\hline & Ennis et al., 2006 [17] & C & 23 & 61.1 & Ulcer & $3 / w k$ & $3-12$ & No \\
\hline & Kavros et al., 2008 [18] & C & 163 & 70.6 & Ulcer & $3 / w k$ & $3-20$ & No \\
\hline & Yao et al., 2014 [19] & B & 8 & 58 & Ulcer & $1-3 / w k$ & 5 & No \\
\hline & Honaker et al., 2013 [20] & C & 85 & 72 & Pressure sore & 10 & $3-20$ & No \\
\hline & Jeffers et al., 2014 [21] & C & 4 & ND & Post-surgical & $5-9$ & ND & ND \\
\hline \multirow[t]{6}{*}{ Coblation } & Richards et al., 2012 [22] & C & 6 & ND & Ulcer $(n=5)$ & 1 & ND & No \\
\hline & & & & & Pressure sore $(n=1)$ & 1 & & \\
\hline & Trial et al., 2012 [23] & C & 25 & ND & Burns $(n=15)$ & 1 & ND & Incomplete graft take $(n=1)$ \\
\hline & & & & & Ulcer $(n=4)$ & & & \\
\hline & & & & & Pressure sore $(n=3)$ & & & \\
\hline & & & & & $N D(n=3)$ & & & \\
\hline
\end{tabular}

[20] did not show any significant gain. No data were found for Coblation therapy (Table 3).

\section{Bacterialload}

In our review, bacterial load was examined only for hydrosurgery, in the study by Liu et al. [14]. There was no significant difference in the quantitative bacterial counts $(\mathrm{P}=0.376)$ (Tables 2 and 3$)$.

\section{Blood loss}

Vanwijck et al. [12], in a series of 167 sub-acute and chronic wounds, described one instance of perioperative bleeding, which was easily controlled. No data were found for ultrasound therapy. Trial et al. [23] emphasized the advantage of a reduction in bleeding when coagulation was employed (Table 3 ).

\section{Healing capacity}

Concerning hydrosurgery, two single-center prospective randomized trials $[10,14]$ compared hydrosurgery performed on 40 patients to conventional debridement performed on $41 \mathrm{pa}-$ tients. Neither study highlighted a significant shortening of wound healing time with hydrosurgery compared to traditional techniques (Tables 2 and 3 ).

For ultrasound therapy, two prospective randomized $[16,19]$ and two retrospective non-randomized $[18,20]$ trials comparing ultrasound therapy were analyzed. These studies involved 241 patients who received ultrasound and 142 who received standard care. Ennis et al. [16] compared ultrasound therapy to placebo in diabetic patients with foot ulcers in a randomized, multicenter, double-blinded study. At 12 weeks, they reported significantly higher healing rates in the treatment group. Kavros et al. [18] reported similar results in patients with leg ulcers as- 
Table 2. Randomized controlled trials

\begin{tabular}{|c|c|c|c|c|c|}
\hline Technique & Study (year) & $\begin{array}{l}\text { Type of } \\
\text { studies }\end{array}$ & $\begin{array}{l}\text { Gold standard: } \\
\text { scalpel or } \\
\text { curette }\end{array}$ & $\begin{array}{l}\text { News } \\
\text { therapies }\end{array}$ & Result \\
\hline \multirow[t]{2}{*}{ Hydrosurgery } & Caputo et al., 2008 [10] & $\begin{array}{l}\text { Unicentric } \\
\text { Prospective } \\
\text { Randomized }\end{array}$ & 22 & 19 & $\begin{array}{l}\text { Significant evidence of a shorter time debridment }(10.8 \mathrm{~min}) \text { using Versajet } \\
\text { over conventional debridment }(17.7 \mathrm{~min})(\mathrm{P}<0.008) \text {. } \\
\text { Median time to wound closure } 71 \text { day (Versajet) vs. } 74 \text { day (conventional) } \\
(\mathrm{P}=0.733) \text {. }\end{array}$ \\
\hline & Liu et al., 2015 [14] & $\begin{array}{l}\text { Unicentric } \\
\text { Prospective } \\
\text { Randomized }\end{array}$ & 19 & 21 & $\begin{array}{l}\text { No significant difference in terms of cost }(P=0.28) \text {. } \\
\text { No significant difference in time to achieve stable wound closure }(P=0.77) \text {. } \\
\text { No difference in quantitative bacterial counts }(P=0.376) \text {. }\end{array}$ \\
\hline \multirow[t]{4}{*}{ Ultrasound } & Ennis et al., 2005 [16] & $\begin{array}{l}\text { Multicentric } \\
\text { Prospective } \\
\text { Randomized }\end{array}$ & 28 & 27 & $\begin{array}{l}\text { Significant reduction in the exudation at wk } 5(P=0.001) \text {. } \\
\text { Mean time to healing shorther in group using ultrasound therapy (9.12 wk) } \\
\text { compare to control ( } 11 \text { wk) }(P=0.0366) \text {. } \\
\text { Proportion of wounds healed at wk } 12 \text { is higher in ultrasound group ( } 40.7 \%) \\
\text { compared to group }(14.3 \%)(P=0.0366) \text {. }\end{array}$ \\
\hline & Kavros et al., 2008 [18] & $\begin{array}{l}\text { Unicentric } \\
\text { Retrospective } \\
\text { Non randomized }\end{array}$ & 47 & 163 & $\begin{array}{l}\text { A significant rates of healing in ischemic }(P=0.049) \text {, neuropathy }(P=0.08) \\
\text { and venous }(P=0.02) \text { wounds. }\end{array}$ \\
\hline & Yao et al., 2014 [19] & $\begin{array}{l}\text { Unicentric } \\
\text { Prospective } \\
\text { Randomized }\end{array}$ & 4 & 8 & No statistically significant difference. \\
\hline & Honaker et al., 2013 [20] & $\begin{array}{l}\text { Unicentric } \\
\text { Retrospective } \\
\text { Non randomized }\end{array}$ & 63 & 43 & $\begin{array}{l}\text { Significant decrease in wound severity between groups for the discharge } \\
\text { assessment }(P<0.005) \text {. }\end{array}$ \\
\hline
\end{tabular}

Table 3. Summary of articles analyzed

\begin{tabular}{|lccccc|}
\hline Technique & Operative time & Cost efficiency & Bacterial load & Blood loss & Healing capacity \\
\hline Hydrosurgery & +++ & $+[10,14]$ & $++[14]$ & No data & $++[10,14]$ \\
Ultrasound & $+[16,20]$ & $++[20]$ & No data & No data & $+++[16,18,19]$ \\
Coblation & No data & No data & No data & $+[23]$ & No data \\
\hline,+ data without statistic test;,++ no statistically significant $P>0.05 ;+++$, statistically significant $P<0.05$. & & \\
\hline
\end{tabular}

sociated with chronic critical limb ischemia. Yao et al. [19] showed a reduction in the percentage of wound area when patients received ultrasound therapy three times a week compared to standard care (Tables 2 and 3 ).

No study investigated the healing time associated with Coblation therapy.

\section{DISCUSSION}

The ideal debridement method should improve tissue sparing, be easy to use even in deep wounds, allow the debridement to be completed quickly, not be hemorrhagic, have a low relative cost compared to repeated dressings, decrease the bacterial load, and improve the global healing rate.

Five debridement methods are currently used: autolytic [1], enzymatic [2], biological [3], surgical/sharp [4], and mechanical methods. Autolytic, enzymatic, and biological methods are selective, but are time-consuming and may cause the destruc- tion of adjacent tissues. Autolytic debridement, which is the body's natural response to necrotic tissue, is painless and selective, but the process is slow [24]. Enzymatic debridement has been suggested as an alternative method, and is useful when other techniques are not feasible during the initial management of a chronic wound [2]. Recently, biodebridement using maggots has become increasingly popular. Larval therapy can be highly selective and rapid [3]. Sharp debridement (scalpel or curette) is the current gold standard [4]. This method is faster but not selective, because it may also remove healthy tissue. This technique is also more hemorrhagic and painful. Finally, mechanical debridement requires a competent practitioner with specialist training, and a hospital admission is necessary [25].

Recently, three innovative methods have emerged: hydrosurgery (Versajet) [5], ultrasound therapy (MIST therapy) [6], and plasma-mediated bipolar radio-frequency ablation (Coblation therapy: Arthrocare) [7].

Hydrosurgery (Supplemental Video S1) has been described as 
an appropriate debridement technique for burns [26,27], venous leg ulcers [28], and pressure ulcers [24]. The Versajet hydrosurgery system is a hydrosurgical device based on the principle of the Venturi effect. In wound debridement, the benefits of irrigation in terms of reducing the bacterial load are well recognized. The wound is flushed with saline solution (at 118-300 $\mathrm{m} / \mathrm{s}$ and 103-827 bar, depending on the 10-step speed setting on the console) to simultaneously remove dead tissue and dilute the bacterial load. The cutting effects can also be manipulated by adjusting the hand piece orientation and pressure, with high precision [28].

Caputo et al. [10] presented significant evidence of shorter debridement times (10.8 minutes) using Versajet over conventional debridement (17.7 minutes). No significant difference in time to achieve stable wound closure and no difference in quantitative bacterial counts $(\mathrm{P}=0.376)$ were found in the study by Liu et al. [14]. This device is interesting for dry necrosis, and according to Klein et al. [5], the device using the Venturi effect seemed to be more conservative than Coblation [5].

In our own experiences, we have observed the Venturi effect to be very effective on dry fibrin and necrotic tissue, but it does not allow hemostasis, limiting its use for large and hemorrhagic wounds.

Ultrasound-based MIST therapy (Supplemental Video S2) devices deliver energy of 0.1 to $0.5 \mathrm{~W} / \mathrm{cm}^{2}$ within the scope of defined treatment. The currently available literature suggests that low-frequency ultrasound is capable of stimulating cellular activity through mechanical energy in the absence of key growth factors, ATP, cytokines, or other enzymes [20]. Signal transduction pathways can be stimulated by ultrasound-generated mechanical energy [16]. MIST ultrasound therapy has been shown to enhance angiogenesis and collagen deposition in a diabetic mouse model [29]. Two phenomena relevant to the mechanisms of ultrasound therapy have been identified: acoustic cavitation and acoustic microstreaming. Acoustic cavitation describes conformational changes caused by the mechanical energy from an ultrasound wave that is absorbed by individual protein molecules [30]. Cavitation occurs with the production and vibration of micron-sized bubbles formed in the tissues, which lead to changes in cell function [31]. Acoustic microstreaming occurs when fluids move along sound wave boundaries, such as cell membranes, resulting in increased protein synthesis and increased permeability of the cell membranes and vascular walls [32]. More research is needed to fully elucidate the mechanisms by which ultrasound energy may contribute to the tissue repair process on a cellular level.

A study of MIST therapy by Ennis et al. [16] showed a significant reduction in exudation at week $5(\mathrm{P}=0.001)$. Furthermore, the mean time to healing was shorter in the group using ultrasound therapy (9.12 weeks) than in the control group (11 weeks) $(\mathrm{P}=0.0366)$, and a higher proportion of wounds had healed by week 12 in the ultrasound group (40.7\%) than in the control group (14.3\%) $(\mathrm{P}=0.0366)$. Of the 133 initially enrolled patients, 55 were finally analyzed. In an intention-to-treat analysis, no statistically significant difference was found [16]. MIST therapy is easy to use and fast; the average time varied between 3 minutes and 20 minutes [18-20]. Unpublished animal studies demonstrating bacterial disruption after ultrasound therapy were confirmed by scanning electron microscopy. The indications for MIST therapy appear to be simple wounds, with a low density of fibrin, a low risk of bleeding, and some small-area infected wounds. It is thus particularly useful in diabetic patients. This technique is especially relevant for ambulatory patients who require a minimum of three sessions per week [19] for faster wound healing. The technique is very simple and can be performed by nurses.

Concerning plasma-mediated bipolar radio-frequency ablation therapy (Supplemental Video S3), few articles have been published. Conventional electrosurgical devices are based on principles described in 1909 [33]. The original technique used a high current density, generating very high temperatures capable of disintegrating tissue through a pyrolytic process [34]. Coblation uses bipolar radio-frequency to energize molecules via a conductive solution surrounding the active electrode, thus creating a precisely focused plasma field. This plasma wire is offset by approximately $0.5 \mathrm{~mm}$ from the wand tip, enabling a regular debridement depth. Currently, no randomized controlled trials have been published [23]. One study is still in progress (NCT00534781), but no results are available. The importance of biofilms and bacterial colonization in relation to impaired wound healing is receiving significant scientific and clinical attention [35]. In an in vitro study, Sonnergren et al. [36] showed significant microbicidal effects compared to hydrosurgery or standard debridement. The reduction compared with untreated controls was $99.87 \%$ to $99.99 \%(\mathrm{P}<0.0001)$ for all strains (Staphylococcus aureus, Streptococcus pyogenes, Pseudomonas aeruginosa, Escherichia coli and Candida albicans). In contrast to hydrosurgery, there is no risk of spreading aerosolized bacteria [37], so health personnel are less exposed to bacterial contamination in the air. Coblation provides a hemostatic effect [23], which is particularly interesting for chronic inflammatory wounds and for patients receiving anticoagulant therapy. It is appropriate for the preparation of skin grafts and causes no bleeding, thus allowing a one-time closure. The Coblation technology may be indicated for any type of debridement involving fibrotic and fatty necrosis debridement and wound bed prepara- 


\section{Fig. 2. Technical characteristics of these procedures}

(A) Versajet hydrosurgery system, (B) MIST therapy device and (C) ArthroCare.

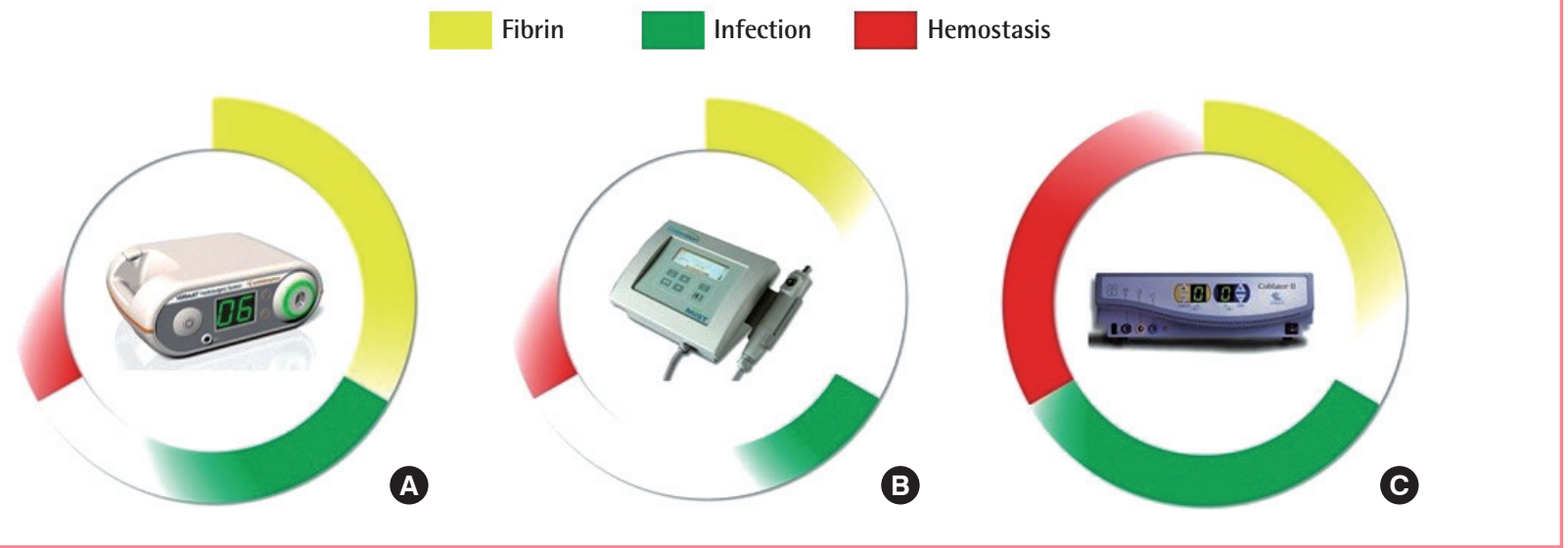

tion [23]. In our experience [23], this device was most useful for fibrotic, infected, and hemorrhagic wounds. This instrument has gradually replaced the use of hydrosurgery. It also seems to us to be more accurate and more convenient than hydrosurgery. However, the wear of the filaments limits its use for wounds of which the surface is less than $5 \%$ of the total body surface.

The treatment cost for the MIST therapy system is US dollar (USD) 9,870 per patient for 26 weeks based on three treatments per week. The rental cost per treatment was estimated to be USD 8, assuming that one MIST therapy system would be used on five patients per day for 5 days a week. Its consumables cost was calculated to be USD 45 per treatment. The treatment cost for MIST therapy also included wound dressing costs at USD 9 per treatment and nursing time at USD 65 per visit. The cost of a Versajet console was USD 7,500 to 9,000, and each hand piece was USD 300. It has been estimated by the manufacturer that the cost per treatment was USD 340 for the technology and USD 550 for staff and operating theater time. Comparatively, the cost of a Coblation console was USD 4,000 and that of a hand piece was USD 500.

\section{PRACTICAL APPROACH}

The analysis of this review and the extrapolation of our experience concerning hydrosurgery (150 procedures), Coblation ( 200 procedures), and ultrasound therapy ( 50 procedures) have allowed us to identify a practical approach:

- Coblation therapy seems to be particularly useful for dry fibrotic, infected, and bleeding wounds, typically chronic ulcers or small deep burns.

- Hydrosurgery can be used for infected [13], fibrinous [5] wounds and intermediate-depth and large burns.
- Finally, ultrasound seems useful in wounds with a low density of fibrin, a low risk of bleeding, and a small infected area, as in diabetic foot ulcer lesions or small leg ulcers that require frequent attention, often from a nurse.

We summarize these indications in Fig. 2.

Our study had several limitations. First, no study included in this review compares the three techniques, and the practical approach was developed based on our own experiences, without specific scientific evidence.

\section{CONCLUSIONS}

Compared to standard debridement techniques with a scalpel or curette, ultrasound therapy showed a significant reduction in healing time and a shorter operating time, which may be associated with an indirect financial gain. No comparative study dedicated to Coblation was identified.

This systematic review highlighted the progress of these three methods and proposed an optimal use for each based on our personal experiences. However, further randomized controlled trials are needed to evaluate and compare these three innovative techniques.

\section{NOTES}

\section{Conflict of interest}

No potential conflict of interest relevant to this article was reported.

\section{Patient consent}

The patients provided written informed consent for the publication and the use of their images. 


\section{Author contribution}

FB and JV: concept and design of study, data acquisition, statistical analysis, and interpretation. Drafting revision and approval of final manuscript to be submitted. $\mathrm{CH}$ and $\mathrm{BC}$ : concept and design of study, data acquisition, critical revision, and approval of final manuscript to be submitted. SF, RM, ADR, GB, JLL: critical revision and approval of final manuscript to be submitted. VG: validation of methodology. Other authors: critical revision and approval of final manuscript to be submitted.

\section{REFERENCES}

1. Cuschieri L, Debosz J, Miiller P, et al. Autolytic debridement of a large, necrotic, fully occluded foot ulcer using a hydrocolloid dressing in a diabetic patient. Adv Skin Wound Care 2013;26:300-4.

2. Smith RG. Enzymatic debriding agents: an evaluation of the medical literature. Ostomy Wound Manage 2008;54:16-34.

3. Shi E, Shofler D. Maggot debridement therapy: a systematic review. Br J Community Nurs 2014;19 Suppl 12:S6-13.

4. Teot L. Debridement, a strategic choice. Soins 2011;(752): 30-3.

5. Klein MB, Hunter S, Heimbach DM, et al. The Versajet water dissector: a new tool for tangential excision. J Burn Care Rehabil 2005;26:483-7.

6. Keltie K, Reay CA, Bousfield DR, et al. Characterization of the ultrasound beam produced by the MIST therapy, wound healing system. Ultrasound Med Biol 2013;39:123340.

7. Bortnick DP; Plastic Surgery Educational Foundation DATA Committee. Coblation: an emerging technology and new technique for soft-tissue surgery. Plast Reconstr Surg 2001;107:614-5.

8. OCEBM Levels of Evidence Working Group. The Oxford 2011 levels of evidence [Internet]. Oxford: Oxford Centre for Evidence-Based Medicine; c2011 [cited 2018 Jan 18]. Available from http://www.cebm.net/index.aspx?o=5653.

9. Gurunluoglu R. Experiences with waterjet hydrosurgery system in wound debridement. World J Emerg Surg 2007; 2:10.

10. Caputo WJ, Beggs DJ, DeFede JL, et al. A prospective randomized controlled clinical trial comparing hydrosurgery debridement with conventional surgical debridement in lower extremity ulcers. Int Wound J 2008;5: 288-94.

11. Dillon CK, Lloyd MS, Dzeiwulski P. Accurate debridement of toxic epidermal necrolysis using Versajet. Burns 2010;36: 581-4.

12. Vanwijck R, Kaba L, Boland S, et al. Immediate skin grafting of sub-acute and chronic wounds debrided by hydrosurgery. J Plast Reconstr Aesthet Surg 2010;63:544-9.

13. Fraccalvieri M, Serra R, Ruka E, et al. Surgical debridement with VERSAJET: an analysis of bacteria load of the wound bed pre- and post-treatment and skin graft taken. A preliminary pilot study. Int Wound J 2011;8:155-61.

14. Liu J, Ko JH, Secretov E, et al. Comparing the hydrosurgery system to conventional debridement techniques for the treatment of delayed healing wounds: a prospective, randomised clinical trial to investigate clinical efficacy and costeffectiveness. Int Wound J 2015;12:456-61.

15. Sivrioglu N, Irkoren S. Versajet hydrosurgery system in the debridement of skin necrosis after Ca gluconate extravasation: report of 9 infantile cases. Acta Orthop Traumatol Turc 2014;48:6-9.

16. Ennis WJ, Foremann P, Mozen N, et al. Ultrasound therapy for recalcitrant diabetic foot ulcers: results of a randomized, double-blind, controlled, multicenter study. Ostomy Wound Manage 2005;51:24-39.

17. Ennis WJ, Valdes W, Gainer M, et al. Evaluation of clinical effectiveness of MIST ultrasound therapy for the healing of chronic wounds. Adv Skin Wound Care 2006;19:437-46.

18. Kavros SJ, Liedl DA, Boon AJ, et al. Expedited wound healing with noncontact, low-frequency ultrasound therapy in chronic wounds: a retrospective analysis. Adv Skin Wound Care 2008;21:416-23.

19. Yao M, Hasturk H, Kantarci A, et al. A pilot study evaluating non-contact low-frequency ultrasound and underlying molecular mechanism on diabetic foot ulcers. Int Wound J 2014;11:586-93.

20. Honaker JS, Forston MR, Davis EA, et al. Effects of non contact low-frequency ultrasound on healing of suspected deep tissue injury: a retrospective analysis. Int Wound J 2013;10:65-72.

21. Jeffers AM, Maxson PM, Thompson SL, et al. Combined negative pressure wound therapy and ultrasonic MIST therapy for open surgical wounds: a case series. J Wound Ostomy Continence Nurs 2014;41:181-6.

22. Richards AJ, Bosanquet DC, Jones N, et al. The ongoing development of a plasma-mediated bipolar radio-frequency ablation device for wound debridement. Wound Int 2012; 4:28-30.

23. Trial C, Brancati A, Marnet O, et al. Coblation technology for surgical wound debridement: principle, experimental data, and technical data. Int J Low Extrem Wounds 2012;11:28692.

24. Mosti G, Iabichella ML, Picerni P, et al. The debridement of hard to heal leg ulcers by means of a new device based on 
Fluidjet technology. Int Wound J 2005;2:307-14.

25. Falabella AF. Debridement and wound bed preparation. Dermatol Ther 2006;19:317-25.

26. Rennekampff HO, Schaller HE, Wisser D, et al. Debridement of burn wounds with a water jet surgical tool. Burns 2006;32:64-9.

27. Cubison TC, Pape SA, Jeffery SL. Dermal preservation using the Versajet hydrosurgery system for debridement of paediatric burns. Burns 2006;32:714-20.

28. Duteille F, Perrot P. Management of 2 nd-degree facial burns using the Versajet ${ }^{\circledR}$ ) hydrosurgery system and xenograft: a prospective evaluation of 20 cases. Burns 2012;38:724-9.

29. Thawer HA, Houghton PE. Effects of ultrasound delivered through a mist of saline to wounds in mice with diabetes mellitus. J Wound Care 2004;13:171-6.

30. Webster DF, Pond JB, Dyson M, et al. The role of cavitation in the in vitro stimulation of protein synthesis in human fibroblasts by ultrasound. Ultrasound Med Biol 1978;4:34351.

31. Sussman C, Dyson M. Therapeutic and diagnostic ultrasound. In: Sussman C, Bates-Jensen BM, editors. Wound care: a collaborative practice manual for health professionals. 3rd ed. Philadelphia: Lippincott Williams \& Wilkins; 2007. p.613-43.

32. Lai J, Pittelkow MR. Physiological effects of ultrasound mist on fibroblasts. Int J Dermatol 2007;46:587-93.

33. Doyen E. Chronic maxillary sinusitis and penicillin. Ann Otolaryngol 1952;69:680-97.

34. Haemmerle G, Duelli H, Abel M, et al. The wound debrider: a new monofilament fibre technology. Br J Nurs 2011;20:S3542.

35. Wolcott RD, Rhoads DD, Bennett ME, et al. Chronic wounds and the medical biofilm paradigm. J Wound Care 2010;19: 45-53.

36. Sonnergren HH, Strombeck L, Aldenborg F, et al. Aerosolized spread of bacteria and reduction of bacterial wound contamination with three different methods of surgical wound debridement: a pilot study. J Hosp Infect 2013;85:112-7.

37. Bowling FL, Stickings DS, Edwards-Jones V, et al. Hydrodebridement of wounds: effectiveness in reducing wound bacterial contamination and potential for air bacterial contamination. J Foot Ankle Res 2009;2:13.

Supplemental Video S1. Versajet hydrosurgery system (Smith \& Nephew).

Supplemental data can be found at: https://doi.org/10.5999/aps.2016.02019.v001

Supplemental Video S2. MIST therapy device (Celleration).

Supplemental data can be found at: https://doi.org/10.5999/aps.2016.02019.v002

Supplemental Video S3. Coblation (Arthrocare ENT).

Supplemental data can be found at: https://doi.org/10.5999/aps.2016.02019.v003 